\title{
POSSIBILIDADES DE FORMAÇÃO PROFISSIONAL OFERECIDAS PELO CENTRO DE CONVIVÊNCIA INFANTIL DA UNESP DE PRESIDENTE PRUDENTE: O INTRAINSTITUCIONAL E O EXTRAINSTITUCIONAL
}

Renata Pavesi, Elaine Fernanda Dornellas de Souza

Especialização Lato-sensu em Gestão Escolar da Universidade do Oeste Paulista - UNOESTE. E-mail: renatapavesi@hotmail.com

\section{RESUMO}

A partir do estágio supervisionado em Gestão Escolar desenvolvido no Centro de Convivência Infantil da UNESP de Presidente Prudente, identificamos e descrevemos quais as possibilidades de contribuição para a formação profissional que a instituição pode oferecer. Ressaltamos a importância do processo de contínuo de construção do profissional de educação e a necessidade de oportunidades de formação e qualidade de formação para que se contribua veementemente com esse profissional. Deste modo duas vias de formação foram identificadas e denominadas de intrainstitucional - tem como agentes protagonistas a equipe de profissionais da instituição e o extrainstitucional - tem como agentes protagonistas o público externo a instituição, vinculado a Universidade e/ou comprometidos com a Educação Infantil.

Palavras chave: formação profissional - educação - formação inicial - Centro de Convivência Infantil - Universidade

\section{INTRODUÇÃO}

Sabemos que é no ingresso do curso de graduação que a formação profissional se inicia, são anos dedicados a adquirir conhecimento teórico e prático para que ao fim se obtenha a titulação que torna o acadêmico legalmente apto para atuar na área a qual escolheu para desenvolver-se profissionalmente.

Já inserido no mercado de trabalho, visando a aquisição e a manutenção de um trabalho de qualidade é indispensável, em qualquer área de atuação, que a atualização e formação continuada estejam presentes e seja uma prática recorrente. Tratando-se do profissional de educação compreendemos que atualizar-se deve tornar-se um hábito, como nos aponta Vasconcellos:

\footnotetext{
"A tarefa do professor é extremamente importante e complexa: deve estar preparado para exerce-la, ou melhor, considerando que a prática é dinâmica e aberta, e que o professor não se propõe a realizar uma atividade e repetitiva, deve estar constantemente se qualificando para exerce-la. Tal qualificação, portanto, não se dá necessariamente a priori; pode se dar antes (reflexão para a ação), durante (reflexão na ação) e após a pratica (reflexão sobre a ação e sobre a reflexão para e na ação). Mesmo quem saiu dos melhores centros universitários sabe que não domina tudo o que a atividade educativa exige, tendo necessidade de aprimoramento contínuo". (Vasconcellos, p.122-123, 2008)
} 
E nesta mesma perspectiva, Lima e Santos fala da necessidade do processo contínuo de construção e reconstrução do profissional de educação:

"A profissão de educador nasce do exercício da função educativa, que por sua vez nasce de necessidades sociais concretas e toma o perfil exigido/desejado/conseguido socialmente. Assumindo diferentes perfis, construindo-se cotidianamente, a identidade profissional desdobra-se, por sua vez, em diferentes posicionamentos entre rupturas e permanências, mas sem perder de vista a sua atribuição maior na convergência da formação de si e do outro". (Lima, P. G. e Santos, 2007, p. 84)

Considerando este movimento de construir e descontruir-se cotidianamente compreendemos que a formação continuada, a formação do profissional de educação, deve ter um cuidado destinado a ela, pensamos em oportunidades de formação e qualidade de formação para que se contribua veementemente com esse profissional. A formação dos profissionais ocorre das mais diferentes maneiras nas instituições, cada uma buscando atender as necessidades, focando a obtenção de resultados satisfatórios e desta forma tornando visível o desempenho de sua equipe escolar. Sobre esta importância das instituições de ensino no processo de formação profissional, Vasconcellos nos diz que:

“A escola não pode ser vista apenas como local de trabalho; deve ser ao mesmo tempo espaço de formação. È preciso investir prioritariamente na formação permanente e em serviço do professor, para que possa ter melhor compreensão do processo educacional, postura e métodos de trabalho mais apropriados". (Vasconcellos, 2008, p. 123)

Assim, como já explicitado neste artigo, vamos nos fixar aos diferentes processos relacionados a formação profissional, que permeiam o cotidiano e a dinâmica do Centro de Convivência Infantil da UNESP de Presidente Prudente serão identificados e categorizados.

Desta forma, temos como objetivo, identificar quais as possibilidades de contribuição para a formação profissional que a instituição pode oferecer tanto para os profissionais da instituição como para o público externo e que de alguma forma esteja vinculado a Universidade ou a Educação Infantil. Para facilitar a compreensão estipulamos duas categorias distintas de formação profissional para separar as duas vias de desenvolvimento profissional observadas intrainstitucional e extrainstitucional. 


\section{METODOLOGIA}

Para idealizar esta pesquisa, nos pautamos em artigos científicos, livros e documentos oficiais da instituição (Universidade Estadual Paulista e Centro de Convivência Infantil) associados as vivências do estágio supervisionado em Gestão Escolar realizado na instituição fonte de análise. Utilizamos a reflexão teórico-crítica sobre o material obtido, relacionando-o a análise das práticas empregadas que foram verificadas na instituição.

\section{Contribuições para a formação profissional: definindo os processos intrainstitucional e extrainstitucional}

Quando falamos em processo intra e extrainstitucional nos referimos ao duplo processo vivenciado por todo o Centro de Convivência Infantil: em uma primeira instância propiciar formação continuada a seus profissionais e num segundo momento, colaborar com a formação inicial dos profissionais que frequentam a Universidade a qual a creche esta vinculada, e que procuram a mesma para desenvolver projetos, estágios e outras práticas relacionadas a formação acadêmica. Ambos acontecem no interior da instituição, sendo que o primeiro tem como agentes protagonistas a equipe de profissionais da instituição e o segundo tem como agentes protagonistas o público externo a instituição, vinculado a Universidade e/ou comprometidos com a Educação.

Assim ao processo de formação profissional dos servidores técnicos-administrativos do Centro de Convivência Infantil relacionado ao aprimoramento de seu desempenho e prática correlatos a função que exerce junto a universidade, denominaremos Formação Intrainstitucional. Sobre este tipo de formação a Política Nacional de Educação Infantil: pelo direito das crianças de zero a seis anos à Educação do Governo Federal prevê que:

- A formação inicial e a continuada das professoras e professores de Educação Infantil são direitos e devem ser asseguradas a todos pelos sistemas de ensino com a inclusão nos planos de cargos e salários do magistério.

- Os sistemas de ensino devem assegurar a valorização de funcionários não-docentes (entende-se por não-docentes todos os funcionários da educação que não atuam em salas de atividades com as crianças) que atuam nas instituições de Educação Infantil, promovendo sua participação em programas de formação inicial e continuada. (Brasil, 2006, p.20)

Este tipo de formação também esta previsto em diversos pontos do Regimento dos Centros de Convivência Infantil que conduzem as práticas e ações empregadas junto aos mesmos (são 14 
CCls espalhados pelo Estado de São Paulo nos diferentes câmpus da UNESP). O artigo 7ำ do Regimento apresenta as atribuições dos Centros de Convivência Infantil, dentre elas:

XI - garantir a formação continuada e permanente como direito de seus profissionais, promovendo e incentivando também a participação em reuniões de caráter pedagógico, em eventos acadêmicos e culturais, bem como criar condições para a realização mensal de capacitação. (RESOLUÇÃO UNESP № 07, DE 15 DE FEVEREIRO DE 2013)

Já o artigo 9o do Regimento aborda o que compete a PRAD - Pró-Reitoria de Administração com relação a formação profissional e manutenção da qualidade do trabalho nos CCls:

II - acompanhar e avaliar o desenvolvimento dos CCls, propondo medidas para seu aperfeiçoamento;

III - elaborar, executar e avaliar projetos de formação continuada e permanente para o desenvolvimento dos servidores; (RESOLUÇÃO UNESP № 07, DE 15 DE FEVEREIRO DE 2013)

E por fim em seu Artigo 18 - Compete à Comissão Técnica assessorar a PRAD no que se refere à:

V - integrar os diversos campos do conhecimento presentes na Universidade, para o desenvolvimento de programas de estudos, pesquisas e projetos nos CCls;

VI - elaborar, implantar e avaliar programas de educação continuada e outras formas de aperfeiçoamento, buscando oferecer condições de desenvolvimento aos profissionais dos CCls; (RESOLUÇÃO UNESP № 07, DE 15 DE FEVEREIRO DE 2013)

A formação intrainstitucional no Centro de Convivência Infantil, conforme definimos e descrevemos, ocorre em momentos distintos e diversificados com periodicidade variada, são eles:

- Semana de planejamento - 5 dias úteis seguidos após as férias coletivas de janeiro destinados exclusivamente para formação continuada da equipe visando a organização e preparação para o período que se inicia;

- Reuniões de equipe - realizadas mensalmente, todo $10^{\circ}$ dia útil de cada mês no período da tarde. Toda a equipe do $\mathrm{CCl}$ se reúne para tratar de assuntos pertinentes ao momento: necessidades, dificuldades e ações que precisam ser analisadas e/ou metas e objetivos que precisam ser pensados para ações futuras.

- Orientações com a supervisão - ocorre uma vez por mês no período da manhã, com encontros de 1 a 2 horas de duração. Momento definido com base nas necessidades da 
unidade de Presidente Prudente oriundo da percepção cotidiana das educadoras e da supervisora que verificaram a necessidade destes encontros de forma mais frequente.

- ADP/Acompanhamento de Desempenho Profissional - é feito anualmente e engloba todos os servidores da UNESP, de todo o Estado, se inicia no mês de abril de determinado ano e finaliza no mês de março do ano subsequente. De acordo com a Portaria Unesp no 359 de 15 de agosto de 2006, que regulamenta o sistema de ADP, ele tem como objetivo o desenvolvimento institucional. Consideramos este instrumento de avaliação de grande valia no processo de formação dos profissionais, pois propicia ao servidor a reflexão sobre suas ações e a melhor compreensão do seu papel e da função que exerce dentro da Universidade.

- Formação livre - A este tipo de formação definiremos aquela que se dá por livre iniciativa do servidor, mas que estejam correlatos com a sua função e formação profissional. Este tipo de busca de conhecimento também propicia a possibilidade de promoção dentro da Universidade.

- Formação oferecida pela Comissão Técnica dos CCls - está comissão é formada por diferentes profissionais (professores doutores em Educação Infantil, supervisores de $\mathrm{CCl}$, psicólogo, dentre outros profissionais) e é responsável por unificar e manter de forma coerente o trabalho de são desenvolvidos nos diferentes $\mathrm{CCl}$ espalhados pelo Estado e ao mesmo tempo respeitar as peculiaridades e particularidades de cada unidade. A comissão faz visitas periódicas aos centros, formação constante com as supervisoras e curso de formação com os servidores dos CCls.

Estes são os meios que, atualmente, compõe o roll de ações que envolvem a formação dos servidores técnicos-administrativos do Centro de Convivência Infantil.

Já ao processo de formação extrainstitucional, denominamos aquele que envolve os acadêmicos dos mais diferentes níveis de formação da Universidade e que esteja relacionado aos programas de estágio e de bolsas concedidos pela Universidade e ainda o outros profissionais que sejam interessados pela Educação Infantil. No campo do ensino, pesquisa e extensão os Centros de Convivência Infantil tem colaborado em diferente níveis de formação dos profissionais do ensino superior (campo de estágio e elaboração de teses e dissertações de pós-graduandos latosensu e stricto sensu e também de graduandos), ações essas que são previstas no Regimento Internos dos CCls em seu artigo 74:

"Os CCls tornar-se-ão espaço de ensino, pesquisa e extensão por meio do desenvolvimento de projetos compatíveis com suas condições de 
funcionamento e organização, devidamente aprovados pela Supervisão e quando for o caso, pela Comissão Técnica. Sobre a este âmbito da formação profissional". (RESOLUÇÃO UNESP № 07, DE 15 DE FEVEREIRO DE 2013)

No Artigo $2^{\circ}$ do mesmo documento, aponta como objetivos dos Centros de Convivência Infantil os seguintes itens:

III - contribuir com a formação de profissionais nas diversas áreas do saber da Universidade, por meio da criação, coordenação e manutenção de estágios, projetos de pesquisa e de extensão relacionados à infância;

IV - elaborar, avaliar e executar projetos que visem ao intercâmbio social, cultural e educacional com a comunidade em geral.( RESOLUÇÃO UNESP № 07, DE 15 DE FEVEREIRO DE 2013)

Atualmente o Centro de Convivência Infantil disponibiliza os seguintes meios para o desenvolvimento e aprimoramento profissional da comunidade externa: desenvolvimento de projetos (relacionado a os cursos de pedagogia, educação física, engenharia ambiental e outros) Programa de Formação Complementar (alunos bolsistas que desenvolvem projetos), Estágio Supervisionado (principalmente do curso de Pedagogia da UNESP), trabalho voluntário (participação em projetos e aquisição de experiência profissional) e visitas de profissionais de outras instituições (professores da rede municipal de Presidente Pudente e de outros municípios e ainda profissionais estrangeiros como a Profa. Dra. Maria João Cardona docente da escola Superior de Educação do Instituto Politécnico de Santarém-Portugal).

\section{CONSIDERAÇÕES FINAIS}

Concluímos que a instituição oferece instrumentos capazes de colaborar no processo de formação profissional de seus servidores e que também contribui de forma efetiva para a complementação de estudos e aquisição de bagagem prática para acadêmicos da Universidade e de outros profissionais da comunidade externa interessados e compromissados com a Educação.

As portas estão abertas, a demanda varia ano a ano, mas é uma constante oscilando de acordo com os interesses e necessidades do alunado da Universidade, bem como da comunidade externa como um todo. Compreendemos que o Centro de Convivência Infantil por ser parte integrante de uma instituição berço de futuros profissionais tem muito a oferecer no âmbito da pesquisa, ensino e extensão, configurando-se num vasto campo para o desenvolvimento de conhecimento cientifico - teórico e prático nas diversas áreas do conhecimento. 


\section{REFERÊNCIAS}

BRASIL, Ministério da Educação e do Desporto, Conselho Nacional de Educação Básica, MEC, Brasília, DCNEI - Diretrizes Curriculares Nacionais para a Educação Infantil, 1998.

BRASIL, Ministério da Educação e do Desporto, Conselho Nacional de Educação Básica, MEC, MEC/SAB, Brasília, Política Nacional de Educação infantil: pelo direito das crianças de zero a seis anos à Educação, 2006 Disponível em: http://portal.mec.gov.br/seb/arquivos/pdf/Educinf/eduinfpolit2006.pdf

Lima, P. G. e Santos, S. M. O COORDENADOR PEDAGÓGICO NA EDUCAÇÃO BÁSICA: DESAFIOS E PERSPECTIVA. Vol. 2 no 4 jul./dez. 2007

Revista de Educação Educere et Educare, p. 77-90. Disponível em: http://www.ufgd.edu.br/faed/nefope/publicacoes/o-coordenador-pedagogico-na-educacaobasica-desafios-e-perspectivas

UNESP. sistema de Acompanhamento de Desenvolvimento Profissional - ADP aos servidores técnicos e administrativos da UNESP. Portaria Unesp no 359 de 15 de agosto de 2006. Disponível em: http://www.unesp.br/prad/sp/mostra_arq_multi.php?arquivo=8131

UNESP. Regimento dos Centros de Convivência Infantil da UNESP. RESOLUÇÃO UNESP № 07, DE 15 DE FEVEREIRO DE 2013. Disponível em:http://unesp.br/Home/cci/resolucao-unesp-07-de-15-defevereiro-2013--alteracao.pdf

VASCONCELLOS, C. S. Coordenação do trabalho pedagógico: do projeto político pedagógico ao cotidiano da sala de aula. São Paulo: Libertad, 2008 